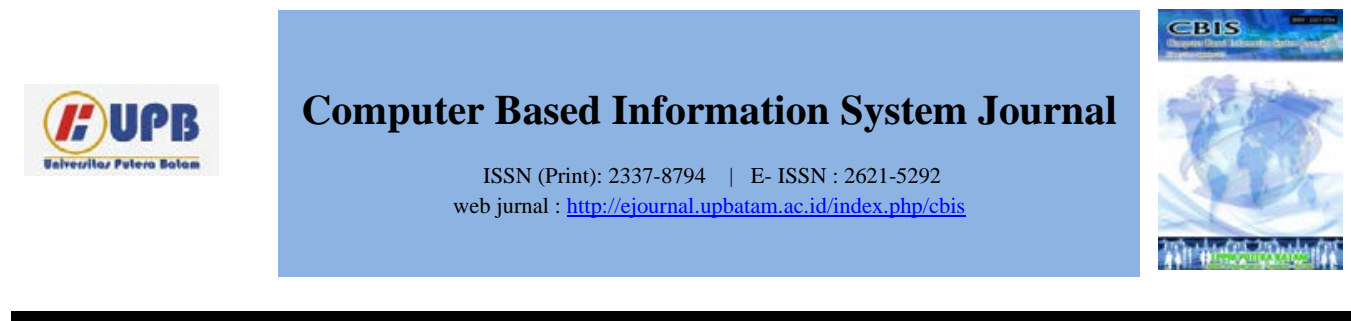

\title{
Perancangan Sistem Informasi Manajemen Bertanam Sayur Berbasis Web
}

\section{Ramdhani D S ${ }^{1}$, Andre $\mathbf{M}^{2}$, Yusril I N ${ }^{3}$, Ghani $A^{4}$, Fajar S ${ }^{5}$}

1 Departemen Teknik dan Ilmu Komputer, Universitas Komputer Indonesia, Indonesia

\section{INFORMASI ARTIKEL}

Diterima Redaksi: August, 2019

Diterbitkan Online: September, 2019

\section{KATA KUNCI}

Sistem Informasi Manajemen

KORESPONDENSI

E-mail: rdsrdn@gmail.com

\begin{abstract}
A B S T R A C T
Abstrak. Tujuan dari penelitian ini adalah untuk merancang sistem informasi manajemen bertanam sayur berbasis web. Pada penelitian ini, penulis menggunakan metode penelitian dalam bentuk metode deskriptif yang menggambarkan masalah yang terjadi di lapangan sebagaimana adanya. Dalam pengumpulan data, penulis melakukan penelitian lapangan dengan observasi dan wawancara, sedangkan dalam pengembangan sistem penulis menggunakan metode life cycle. Hasil dari penelitian ini menunjukan bahwa perlunya sebuah sistem informasi yang menyajikan cara-cara yang baik dan benar untuk menanam sayuran. Kemudian penulis merancang sistem informasi manajemen menanam sayuran berbasis web, sistem ini setiap hari akan memberikan informasi tentang apa yang harus dilakukan dengan tanaman sayuran dari bibit hingga panen. Tidak berguna bagi petani sayuran saja, sistem ini juga berguna bagi orang yang tidak tahu cara menanam sayuran yang baik dan benar. Dengan demikian, produk sayuran di Indonesia bisa meningkat.
\end{abstract}

\section{Latar Belakang}

Dengan pesatnya perkembangan teknologi, di masa yang akan datang semua bidang akan menerapkan teknologi, termasuk pertanian. Pengusaha pada masa sekarang, harus memahami teknologi yang sedang berkembang[1] khususnya yang bergerak di bidang pertanian. Pada saat ini, bidang pertanian sudah mulai menerapkan teknologi yang di sebut smart farming, meski dalam penerapannya belum maksimal, karena hanya di beberapa negara besar saja yang sudah memakai teknologi ini. Penerapan teknologi yang baik akan mengurangi proses tahapan kerja, yang tadinya dilakukan manual digantikan oleh sistem[2]. Salah satu teknologi yang bisa di terapkan dalam bidang pertanian adalah Sistem Informasi Manajemen (SIM)[3][5]. Efisiensi kinerja bisa meningkat jika 
memakai teknologi Sistem Informasi Manajemen[6].

Sayuran merupakan salah satu hasil pertanian yang sangat dibutuhkan oleh manusia untuk memenuhi kebutuhan gizi. Di Indonesia, hasil produksi sayuran pertahunnya tidak merata, hanya beberapa jenis sayuran saja yang produksinya stabil[7]. Pemanfaatkan teknologi Sistem Informasi Manajemen berbasis web, bisa meningkatkan produksi[8].

Dari referensi di atas, belum ada informasi tentang Sistem Informasi Manajemen Bertanam Sayuran. Penelitian ini bertujuan untuk merancang Sistem Informasi Manajemen Bertanam Sayur Berbasis Web. Untuk menganalisis bagaimana perlunya sistem ini, penulis menggunakan metode deskriptif. Pengumpulan data, penulis memakai metode peneilitian lapangan yaitu observasi dan wawancara, sedangkan dalam metode pengembangan sistem penulis menggunakan metode pengembangan life cycle.

\section{Kajian Literatur}

\subsection{Sistem Informasi Manajemen}

Sistem informasi manajemen merupakan perencanaan pengendalian yang memanfaatkan manusia, dokumen, teknologi dan prosedur. Menurut Ali dan Beg, manusia akan mencari informasi yang dia butuhkan melalui web[9]. Pada masa mendatang, sistem informasi manajemen pertanian harus mendukung kelompok - kelompok dan individu[10].

\section{Metode}

Pada penelitian ini, menggunakan metode peneilitan deskriptif. Untuk metode pengumpulan data terdiri dari penelitian lapangan dilakukan dengan obervasi dan wawancara, sedangkan metode pengembangannya menggunakan metode System Development Life Cycle (SDLC). System Development Life Cycle (SDLC) jenisnya ada banyak, tetapi pada perancangan http://ejournal.upbatam.ac.id/index.php/cbis sistem informasi manajemen bertanam sayur ini penulis menggunakan waterfall (lihat gambar 1).

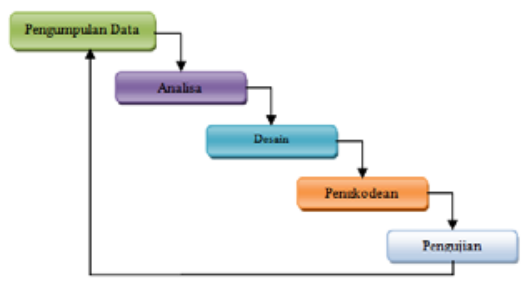

Gambar 1 Waterfall

\section{Hasil dan Pembahasan}

Penerapan teknologi dalam pertanian sangat bermanfaat untuk meningkatkan hasil produksi. Salah satu teknologi yang bisa diterapkan dalam pertanian yaitu sistem informasi manajemen. Sistem informasi manajemen bisa mengendalikan dalam perencanaan pengelolaan pertanian. Karena hal ini penulis merancang sistem informasi manajemen bertanam sayur berbasis web.

Dalam mencari data untuk merancang sistem informasi manajemen ini, penulis observasi dan mewawancara pegawai dari Dinas Pertanian.

Sistem Informasi manajemen ini berisi tata cara bertanam sayuran yang baik dan benar, dari bibit sampai panen. Melihat banyaknya masyarakat yang mempunyai lahan tetapi tidak tahu bagaimana tata cara bertanam sayuran yang baik dan benar, maka sistem informasi manajemen ini bisa memberikan informasi dan tata cara bertanam sayuran. Jadi tidak berguna untuk petani sayuran saja, sistem informasi manajemen ini berguna untuk semua masyarakat yang ingin menanam sayuran.

Sistem informasi manajemen ini menggunakan berbasis web, alasan penulis menggunakan web, karena web mudah di akses dimana saja, kapanpun dan oleh siapapun. Web juga bisa di akses menggunakan perangkat apa saja.

Prosedur sistem informasi manajemen ini dibuat sesuai dengan kebutuhan dan dibuat sederhana agar masyarakat awam yang tidak 
terlalu paham teknologi juga bisa memakainya dan gampang untuk dipahami.

Untuk mengakses sistem informasi manajemen ini, pengguna harus membuat akun terlebih dahulu untuk menjadi member baru bisa memulai bertanam sayurannya.

Setiap harinya sistem infomasi manajemen ini akan memberikan infromasi jadwal perawatan tanaman yang harus dilakukan oleh pengguna. Setelah selesai melakukan perawatan, pengguna harus mengisi data kondisi tanaman setiap harinya.

Pada penelitian ini, penulis merancang prosedur, diagram use case dan tampilan web dari sistem informasi manajemen bertanam sayuran. Penulis merancang halaman utama web, form untuk membuat akun dan pendaftaran anggota baru, halaman utama member, menu daftar sayuran yang bisa di tanam, halaman penjelasan tanaman, halaman memulai menanam, halaman infromasi jadwal perawatan dan halaman form untuk memasukan data kondisi tanaman.

A. Perancangan Prosedur

Dalam perancangan prosedur penulis merancangnya sebagai berikut.

1. Prosedur Pendaftaran Anggota Baru

a. Membuka halaman web.

b.Memilih menu Pendaftaran.

c. Mengisi data berupa ada nama lengkap pengguna, email, namapengguna dan kata sandi.

d.Data yang diisi harus benar, jika sudah diisi, pilih daftar kemudian user akan di arahkan ke tampilan login untuk masuk ke dasboard member.

2. Prosedur Mulai Menanam Sayuran
a. Membuka menu mulai menanam.

b.Di situ member bisa memilih tanaman apa yang akan ditanam.

c. Setelah memilih tanamannya, akan ada penjelasan tentang tanaman yang member pilih.

d.Setelah paham,member bisa memilih tombol Mulai Menanam.

e. Akan muncul form yang harus member isi berupa data tanggal mulai menanam sayur, media apa yang dipakai untuk menanamnya, curah hujan, ketinggian dan kelembaban udara.

f. Setelah semua terisi, klik tombol mulai untuk memulai, setiap harinya akan muncul jadwal perawatan pada menu Sedang di Tanam.

3. Prosedur Laporan Kondisi Tanaman

a. Masuk ke menu sedang di tanam.

b.Member memilih hari ke berapa jadwal terakhir yang sedang berlangsung.

c. Setelah memilih, akan muncul form yang harus diisi berupa tinggi pohon, ada hama atau tidaknya, jenis hama, jumlah buah dan kondisi tanah.

d.Jika sudah diisi klik selesai untuk menyimpan kondisi tanaman.

B. Perancangan Diagram

Pada perancangan diagram, penulis membuat diagram use case dimana di dalam diagram use case ini ada 3 use case yaitu Pendaftaran Anggota Baru, Mulai Menanam dan Laporan Kondisi Tanaman, berikut diagram use case-nya (lihat gambar 2). 


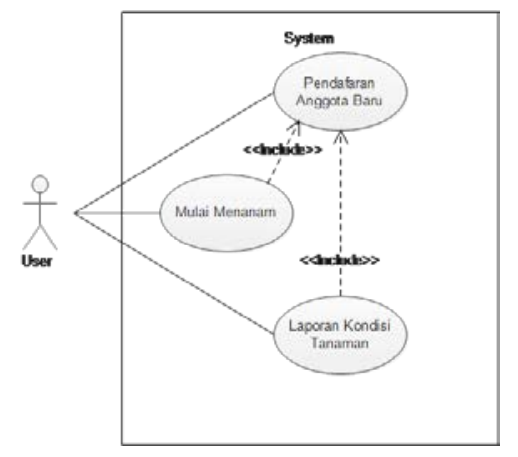

Gambar 2 Diagram Use Case

\section{Perancangan Tampilan}

Untuk lebih jelasnya perancangan sistem informasi manajemen bertanam sayur berbasis web ini, penulis membuat beberapa tampilan sebagai berikut:

\section{Halaman Utama}

Halaman utama ini merupakan tampilan awal ketika pengguna membuka web sistem informasi manajememen bertanam sayur. Pada halaman ini ada menu bar halaman utama, daftar dan masuk. Jika pengguna belum memiliki akun, maka harus membuat akun terlebih dahulu untuk menjadi anggota dengan mengklik menu Daftar, dan jika pengguna sudah memiliki akun anggota maka langsung masuk saja dengan mengklik menu Masuk(lihat gambar 3).
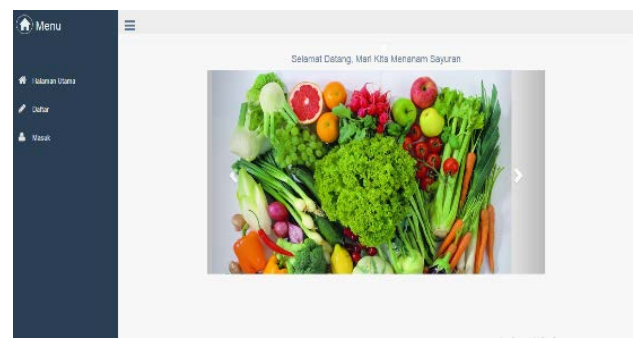

Gambar 3 Halaman Utama

\section{Pendaftaran Anggota Baru}

Halaman pendaftaran pengguna baru adalah halaman untuk menjadi member dan membuat akun baru bagi pengguna baru. Di http://ejournal.upbatam.ac.id/index.php/cbis halaman ini pengguna harus mengisi data dengan benar, data yang harus di isi diantaranya ada nama lengkap pengguna, email, namapengguna dan kata sandi. Setelah mengisi dengan benar, pengguna mengklik tombol daftar, jika datanya salah pengguna tinggal mengklik tombol reset untuk menghapus semua data yang telah diisi(lihat gambar 4).
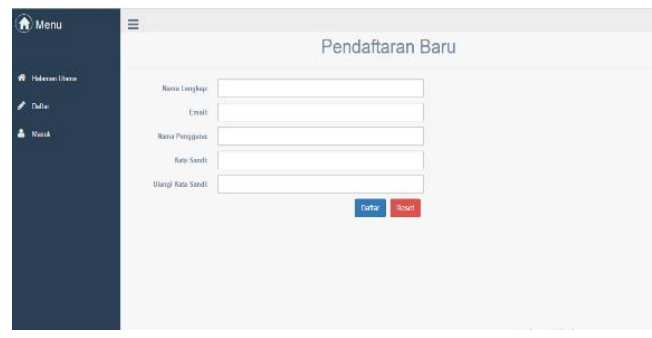

Gambar 4 Pendaftaran Member baru

3. Halaman utama member

Halaman utama member adalah halaman ketika pengguna sudah mempunyai akun member. Pada halaman ini terdapat menu Mulai bertanam, sedang di tanam, pengaturan dan keluar. Menu mulai bertanam adalah halaman untuk member jika akan memulai menanam sayuran. Menu sedang di tanam adalah halaman untuk melihat sayuran apa saja sedang ditanam oleh member,melihat jadwal perawatan dan data kondisi sayuran setiap harinya(lihat gambar 5).
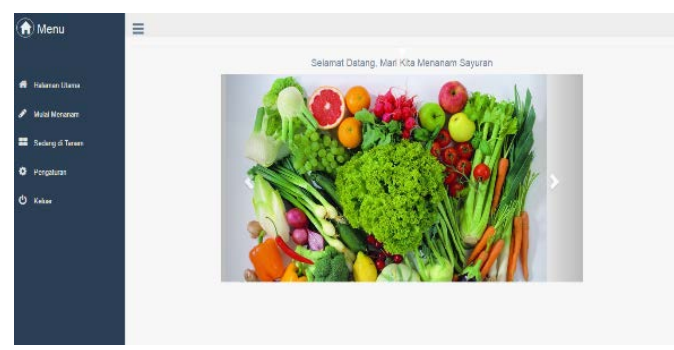

Gambar 5 Halaman utama member 


\section{Menu Daftar Sayuran}

Jika pengguna akan memulai menanam sayur, maka pengguna harus masuk ke halaman ini. Di halaman ini terdapat beberapa jenis sayuran, pengguna tinggal memilih sayur apa yang akan ditanam dengan mengklik gambarnya(lihat gambar 6).
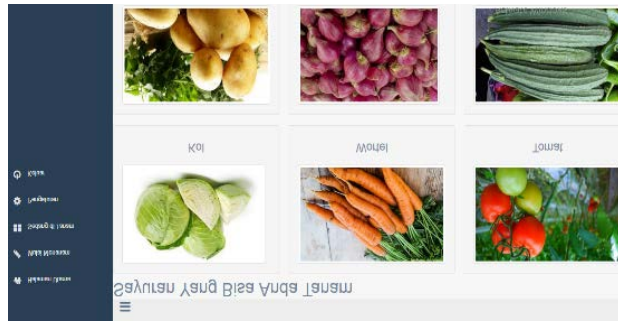

Gambar 6 Daftar Sayuran

\section{Halaman Penjelasan}

Halaman penjelasan adalah halaman yang berisi tentang penjelasan sayur yang akan ditanam oleh pengguna. Jika sudah paham tentang sayur yang akan ditanam, maka pengguna bisa mengklik tombol Mulai Menanam(lihat gambar 7).

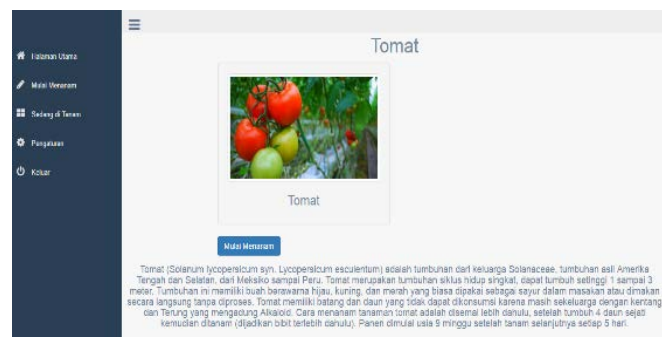

Gambar 7 Halaman Penjelasan

\section{Halaman Mulai Menanam}

Halaman mulai menanam adalah halaman baru setelah pengguna masuk ke halaman penjelasan sayur. Pada halaman ini pengguna akan dikasih tahu syarat agar sayur yang akan ditanam bisa tumbuh dengan baik. Selain itu, pada halaman ini pengguna juga harus mengisi data tanggal mulai menanam sayur, media apa yang dipakai untuk menanamnya, curah hujan, ketinggian dan kelembaban udara. Pengguna harus memperhatikan syarat tumbuh tanaman, agar mendapatkan tanamannya tumbuh dengan baik dan mendapatkan hasil yang maksimal(lihat gambar 8).

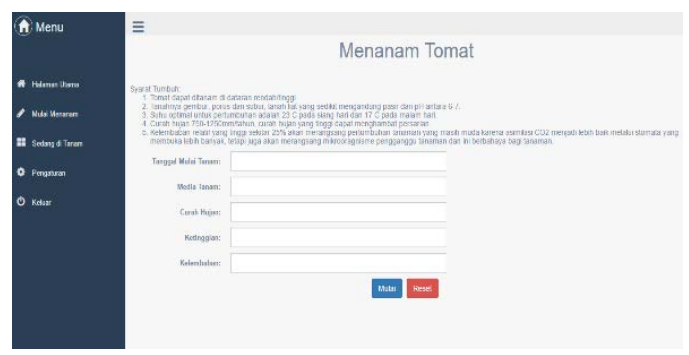

Gambar 8 Halaman Mulai Menanam

\section{Jadwal Perawatan}

Halaman jadwal perawatan adalah halaman yang akan memberikan informasi apa saja yang harus dilakukan pada tanaman setiap harinya sampai tanaman bisa di panen. Halaman ini bisa dibuka pada menu sedang di tanam. Setelah semua jadwal perawatan dilakukan pengguna harus mengklik tombol selesai untuk menutup halaman ini(lihat gambar 9).

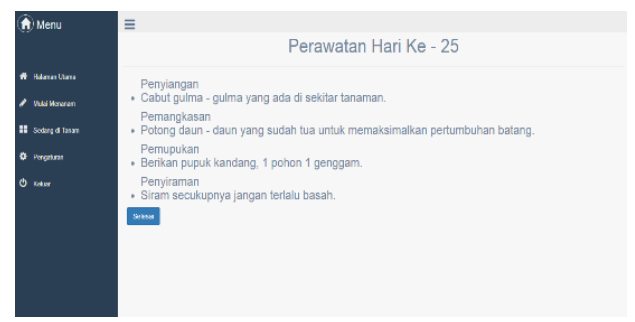

Gambar 9 Jadwal Perawatan

\section{Kondisi Tanaman}

Halaman kondisi tanaman adalah halaman yang harus diisi oleh pengguna berdasarkan kondisi tanaman setiap harinya. Pengguna harus mengisinya dengan benar dan sesuai dengan perkembangan tanaman. Data yang harus diisi ada tinggi pohon, ada hama atau 
tidaknya, jenis hama, jumlah buah dan kondisi tanah(lihat gambar 10).

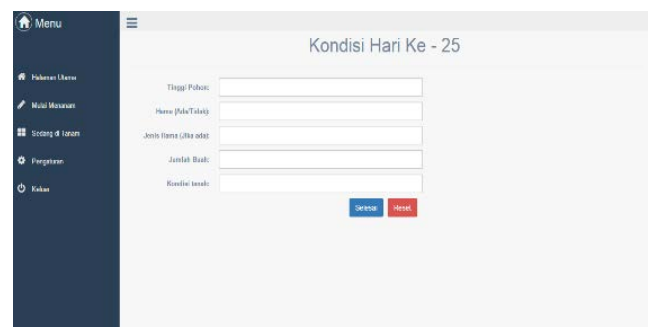

Gambar 10 Kondisi Tanaman

\section{Kesimpulan}

Penerapan teknologi informasi dalam bidang pertanian sangat banyak manfaatnya. Salah satu teknologi informasi yang bisa digunakan dalam bidang pertanian adalah sistem informasi manajemen. Dengan adanya sistem informasi manajemen bertanam sayuran berbasis web, bisa memberikan dampak yang baik, yaitu bisa memberikan informasi bagaimana bertanam sayuran yang baik dan benar. Para petani sayur juga bisa memanfaatkan sistem infromasi manajemen ini untuk menghindari gagal panen dan mendapatkan hasil panen yang maksimal. Selain petani, masyarakat yang tidak tahu bertanam sayur juga bisa memakai sistem informasi manajemen ini untuk panduan bertanam sayur. Penghasilan produksi sayuran di Indonesia bisa meningkat.

\section{Acknowledgement}

Terima kasih kepada Yudi Nugraha dari Dinas Pertanian yang telah bersedia membantu dan menjawab semua pertanyaan penulis. Terima kasih juga untuk semua pihak yang telah membantu penulis.

\section{Referensi}

[1] Dr.Ir. Eddy Soeryanto Soegoto 2014. Enterpreneurship Menjadi Pebisnis Ulung.
[2] Rusli1*, Nurdin Noni2 , Nasrul Ihsan3 \& Ansari Saleh Ahmar4, 2018 . The Development of Research Management Information System Based on Web at Universitas Negeri Makassar, Indonesia. 2nd International Conference on Statistics, Mathematics, Teaching, and Research

[3] Lazim D et al., 2018 Information Management and PSM Evaluation System Int. J. Eng. Technol. 7, 1.6 p. 17-19.

[4] Pontan D et al., 2018 Effect of the building maintenance and resource management through user satisfaction of maintenance Int. J. Eng. Technol. 7, 2 p. 462-465.

[5] Fauzy F A A et al., 2018 Registration System and UTM Games Decision Using the Website Application Int. J. Eng. Technol. 7, 2.2 p. 45-47

[6] Abdullah D Suwilo S Efendi S and Erliana C I, 2018 A Slack-Based Measures for Improving the Efficiency Performance of Departments in Universitas Malikussaleh Int. J. Eng. Technol. 7,

2 p. 491-494

[7] Adiyoga, W 2009. Analisis Trend Hasil Per Satuan Luas Tanaman Sayuran Tahun 1969-2006 di Indonesia, indonesia. J. Hort. 19(4):484-499,

[8] Lee H L and Whang S 2000 Information sharing in a supply chain. International Journal of Manufacturing Technology and Management, 1(1), pp. 79-93.

[9] Ali R \& Beg M S 2017 Introduction. In Applications of Soft Computing for the Web Springer, Singapore. Intternational Journals of Science, 8(6), pp. 1-7.

[10]T Řezník ${ }^{1}$ Ｍ Kepka ${ }^{2}$ ，K Charvát ${ }^{3}$ K Charvát $\mathrm{Jr}^{3}$, S Horákováa ${ }^{3}$ V Lukas ${ }^{4}, 2016$ Challenges of agricultural monitoring: integration of the Open Farm Management Information System into GEOSS and Digital Earth . czech republic. 9th Symposium of the International Society for Digital Earth (ISDE) 